\title{
Cold surge event observed by radiosonde observation from the research vessel "Hakuho-maru" over the Philippine Sea in December 2012
}

\author{
Shin-Ya Ogino ${ }^{1 *}$ (D), Peiming Wu ${ }^{1}$, Miki Hattori ${ }^{1}$, Nobuhiko Endo ${ }^{1,2}$, Hisayuki Kubota ${ }^{1,3}$, Tomoshige Inoue ${ }^{1,4}$ \\ and Jun Matsumoto ${ }^{1,5}$
}

\begin{abstract}
The thermal energy transfer from the sea surface to the atmosphere associated with a cold surge event was investigated with observations from radiosondes on the research vessel "Hakuho-maru" over the Philippine Sea in December 2012. These observations were analyzed, and the results were compared with those obtained from observations over the East China Sea in the Air Mass Transformation Experiment in 1974 (AMTEX '74). The horizontal advection of cold and dry air associated with the cold surge dominated at heights below $850 \mathrm{hPa}$. In spite of this strong advection, the local temporal variations in the temperature and moisture were small, because the advection was balanced by the transfer of heat and moisture from the sea surface, which is qualitatively the same behavior as observed during the cold surge event in AMTEX' 74 . The eddy transport of the total heat energy from the sea surface to the atmosphere was estimated at about $410 \mathrm{~W} / \mathrm{m}^{2}$, which is about half of the maximum value of $780 \mathrm{~W} / \mathrm{m}^{2}$ observed during AMTEX'74. This result shows the existence of considerable heat transfer from the sea surface to the atmosphere over the Philippine Sea, which is the downstream region of the cold surge, after it passed through the East China Sea.
\end{abstract}

Keywords: Cold surge, Air-sea interaction, Air mass transformation, Hakuho-maru, Philippine Sea, VPREX2012, AMY2007-2012

\section{Introduction}

Cold surges originating from the Siberian High are common during the Asian winter monsoon and can extend as far as the Southeast Asia, including the Philippines and the Indochina Peninsula. Two active propagation paths are known: the South China Sea (SCS) path and the Philippine Sea path (Compo et al. 1999). Several studies have shown that the surges along the SCS can result in heavy rainfall along the east coast of the Indochina Peninsula. The coupling of the cold surge and the westward-propagating disturbance in the SCS has been suggested as a key process of increased precipitation over central Vietnam (Yokoi and Matsumoto 2008; Wu et al. 2011; Chen et al. 2012). However, changes in the rainfall over the Philippine Sea area

\footnotetext{
*Correspondence: ogino-sy@jamstec.go.jp

${ }^{1} J a p a n$ Agency for Marine-Earth Science and Technology, 2-15

Natsushima-cho, Yokosuka 237-0061, Japan

Full list of author information is available at the end of the article
}

associated with a cold surge have not yet been carefully investigated.

Air mass transformation is one of the most important processes during a cold surge event, since it determines the thermodynamic features of the air mass that develops into convection and rainfall. However, a quantitative evaluation based on observations has not yet been conducted, except for the Air Mass Transformation Experiment in 1974 (AMTEX '74) (Ninomiya 1975). AMTEX '74 was conducted in February 1974 over the East China Sea, and the observation area is shown in Fig. 1. In the experiment, a cold surge and the associated air-mass transformation over the East China Sea were observed, when the cold surge encountered the sea surface after passing over land. Ninomiya (1975) showed that during the cold period of February 23-27, 1974, cold and dry advection dominated and was almost balanced with the eddy heat supply from the sea, which was confined below the $850 \mathrm{hPa}$ level. The 


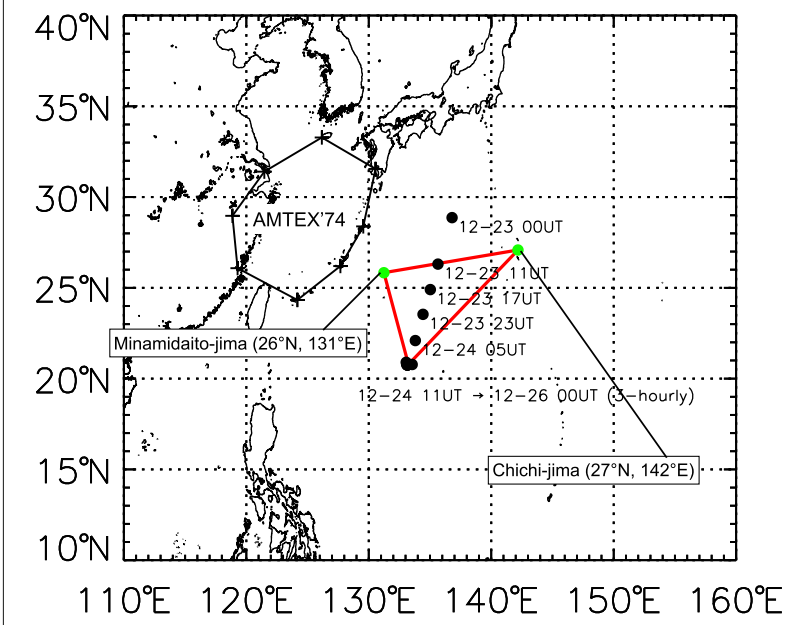

Fig. 1 The observation sites of the radiosondes used in this study. Black circles show the launch position of the radiosondes from the R/ Hakuho-maru. The radiosonde stations at Minamidaitojima and Chichijima are indicated by green circles. The AMTEX '74 observation area is shown by the black polygon

total heat supply from the sea to the atmosphere was estimated at about $580 \mathrm{~W} / \mathrm{m}^{2}$.

In December 2012, we succeeded in observing a cold surge event using radiosondes on the research vessel "Hakuho-maru" (hereafter, R/V Hakuho-maru) over the Philippine Sea. Since the observation area was located downstream of the AMTEX ' 74 observation area, we expected that the R/V Hakuho-maru observations would record the air mass that had already traveled over the East China Sea and had been influenced by the air-sea interaction. In this paper, we present a case study of this cold surge event to understand the air-sea interaction at locations far from land and to compare the results with those obtained from AMTEX '74.

\section{Methods/Experimental Observation and data}

We conducted radiosonde observations from the R/V Hakuho-maru during December 23-26, 2012 as a part of the Vietnam Philippines Rainfall Experiment (VPREX) 2012 (http://www.jamstec.go.jp/rigc/j/tcvrp/ mhcrt/vprex.html) under the Asian Monsoon Year 2007-2012 project (Wang et al. 2010). Figure 1 shows the observation sites and the launch times of the radiosondes. We launched radiosondes at 6- or 12-h intervals during December $23-24$ between $29^{\circ} \mathrm{N}$ and $21^{\circ} \mathrm{N}$ along the cruise track from north to south. At the southernmost site $\left(21^{\circ} \mathrm{N}, 133^{\circ} \mathrm{E}\right)$, we carried out a fixed-point observation at 3-h intervals for about 1.5 days during December 24-25. We then performed an energy budget analysis with the fixed-point observation data combined with the operational radiosonde data from the nearby Japan
Meteorological Agency upper-air stations, Minamidaitojima $\left(26^{\circ} \mathrm{N}, 131^{\circ} \mathrm{E}\right)$ and Chichijima $\left(27^{\circ} \mathrm{N}, 142^{\circ} \mathrm{E}\right)$. We also used the National Centers for Environmental Prediction (NCEP) reanalysis II (Kanamitsu et al. 2002) to examine the large-scale background fields and the Tropical Rainfall Measuring Mission (TRMM) 3B42 data set (e.g., Kummerow et al. 2000) to examine the rainfall intensity.

\section{Thermal and moisture budget analysis}

We performed a thermal and moisture budget analysis and compared the results with those obtained by Ninomiya (1975) from AMTEX '74. In order to compare these results, we used the same formula and vertical coordinates as those used by Ninomiya (1975), which are briefly described below.

The heat energy and moisture continuity equations averaged over a certain area are written as follows:

$$
\begin{aligned}
\frac{\delta T}{\delta t}+\frac{\partial}{\partial p} \overline{\omega^{\prime} T^{\prime}} & =\frac{d T_{R}}{d t}+\frac{L}{C_{p}} m \\
\frac{\delta q}{\delta t}+\frac{\partial}{\partial p} \overline{\omega^{\prime} q^{\prime}} & =-m
\end{aligned}
$$

where $T$ is temperature, $p$ is pressure, $\omega$ is the vertical $p$-velocity, $d T_{R} / d t$ is the heating rate due to net radiation, $C_{p}$ is the specific heat of dry air at constant pressure, $q$ is the water vapor mixing ratio, $L$ is the latent heat of condensation, $m$ is the net condensation, the overbar $\bar{X}$ denotes the area-averaged value of the variable $X$, and the prime $X^{\prime}$ denotes the deviation from $\bar{X}$. The individual changes, the changes in the area-averaged quantities following the motion, of temperature and moisture were calculated from the area-averaged thermodynamic and moisture budget equations as follows:

$$
\begin{aligned}
\frac{\delta T}{\delta t} & =\frac{\partial \bar{T}}{\partial t}+\overline{\boldsymbol{v} \cdot \nabla T}+\bar{\omega}\left(\frac{\partial \bar{T}}{\partial p}-\frac{R}{C_{p}} \frac{\bar{T}}{p}\right), \\
\frac{\delta q}{\delta t} & =\frac{\partial \bar{q}}{\partial t}+\overline{\boldsymbol{v} \cdot \nabla q}+\bar{\omega} \frac{\partial \bar{q}}{\partial p}
\end{aligned}
$$

where $\boldsymbol{v}$ is the horizontal wind and $R$ is the gas constant. The individual change in the equivalent temperature is obtained by eliminating the net condensation $m$ from Eqs. (1) and (2) as follows:

$$
\frac{\delta}{\delta t}\left(T+\frac{L}{C_{p}} q\right)=-\frac{\partial}{\partial p} \overline{\omega^{\prime}\left(T^{\prime}+\frac{L}{C_{p}} q^{\prime}\right)}+\frac{d T_{R}}{d t}
$$

By integrating Eq. (5) from the surface $\left(p_{\mathrm{SFC}}\right)$ to a given pressure level $(p)$, the eddy transport of the total heat energy $F_{c}=-1 / g\left(C_{p} \overline{\omega^{\prime} T^{\prime}}+L \overline{\omega^{\prime} q^{\prime}}\right)$ can be evaluated as follows: 


$$
\begin{aligned}
F_{c}(p)= & -\frac{1}{g} \int_{p}^{p_{\mathrm{SFC}}} \frac{\delta}{\delta t}\left(C_{p} T+L q\right) d p-\frac{1}{g} F_{c}\left(p_{\mathrm{SFC}}\right) \\
& +\frac{C_{p}}{g} \int_{p}^{p_{\mathrm{SFC}}} \frac{d T_{R}}{d t} d p
\end{aligned}
$$

where $g$ is the gravitational acceleration, the second term on the right-hand side can be evaluated beforehand by integrating Eq. (5) from the surface to the top level under the assumption that the eddy heat and moisture transport vanish at the top level as described below, and the third term on the right-hand side can be evaluated by assuming that the radiative heating rate at each layer is as described below.

The area-average of the abovementioned thermodynamic quantities was calculated from the data obtained at R/V Hakuho-maru, Minamidaitojima, and Chichijima. The horizontal gradient and the horizontal divergence were calculated by fitting of the plane surface to the data from the three observation stations as in Davies-Jones (1993).

As in Ninomiya (1975), we evaluate the thermodynamic quantities in three layers: (1) between the surface and $850 \mathrm{hPa}$, (2) between 850 and $700 \mathrm{hPa}$, and (3) between 700 and $500 \mathrm{hPa}$. We assume that the eddy transport of heat and moisture vanish at $500 \mathrm{hPa}$.

The vertical $p$-velocity was estimated by accumulation of the horizontal divergence. The surface vertical $p$-velocity was calculated from the time derivative of the surface pressure. The original estimate of the vertical $p$ velocity $\omega_{\text {org }}$ was adjusted in order to reduce the estimate errors as follows:

$$
\begin{aligned}
\omega & =\omega_{\text {org }}-\Delta \omega \\
& =\omega_{\text {org }}-\left(p-p_{\text {sfc }}\right) \frac{\omega_{\text {org,top }}-\omega_{\text {top }}}{p_{\text {top }}-p_{\text {sfc }}},
\end{aligned}
$$

where subscripts top and sfc denote the top level $(500 \mathrm{hPa}$ in this study) and the surface, respectively. The vertical $p$-velocity at the top level $\omega_{\text {top }}$ was estimated by

$$
\omega_{\text {top }}=-\left(\frac{\partial \bar{T}}{\partial t}+\overline{\boldsymbol{v} \cdot \nabla T}-\frac{d T_{R}}{d t}\right) /\left(\frac{\partial \bar{T}}{\partial p}-\frac{R}{C_{p}} \frac{\bar{T}}{p}\right),
$$

and assuming thermodynamic balance between the adiabatic motion and the radiative heating. This assumption is reasonable because condensation and evaporation did not seem to occur under the dry conditions observed at this level (the relative humidity was under $40 \%$, not shown), and the eddy heat transport from the sea surface did not seem to penetrate the $700 \mathrm{hPa}$ pressure level as discussed later.

For the radiative heating rate $d T_{R} / d t$, the climatological values near $20^{\circ} \mathrm{N}$ and $135^{\circ} \mathrm{E}$ taken from Katayama (1967) are used as in Ninomiya (1975). They are $-0.042,-0.034$, and $-0.062 \mathrm{~K} / \mathrm{h}$ for the layers between the surface and at $850 \mathrm{hPa}, 850-700 \mathrm{hPa}$, and $700-500 \mathrm{hPa}$, respectively, and are insignificant compared with the other terms in the budget analysis of this study (e.g., the change in the equivalent temperature in the near-surface layer was estimated as about $0.5 \mathrm{~K} / \mathrm{hr}$ ).

The net condensation $m$ was assumed to be zero, as we found no TRMM 3B42 precipitation over the analysis area during the analysis period (from 1200 UT on December 24 to 1200 UT on December 25).

\section{Results}

\section{Synoptic situation}

Figure 2 shows the distributions of the synoptic fields at $925 \mathrm{hPa}$ and their temporal variations during the Hakuho-maru observation period. A tongue shaped ridge extending from the southeastern edge of the strengthened Siberian High appeared on December 21 (the upper panel of Fig. 2). On December 23 (the middle panel of Fig. 2), at the beginning of the observation period at the northernmost site $\left(29^{\circ} \mathrm{N}\right)$, an anticyclone with cold air was separated from the southeastern edge of the Siberian High, which was weakened on the same day, and moved to the southern region of China. This anticyclone enhanced the northeasterly flow over the northern Indochina and SCS regions. These variations are typical characteristics of a SCS cold surge (e.g., Compo et al. 1999).

On the same day, a weak ridge was found in the East China Sea (around $30^{\circ} \mathrm{N}, 125^{\circ} \mathrm{E}$ ) and the associated northwesterly flow reached the Hakuho-maru observation area after passing through the East China Sea. On December 26 (the lower panel of Fig. 2), the ridge became more pronounced and moved southeastward to reach the Hakuhomaru observation area, just as we finished the fixed-point observations at the southernmost site $\left(21^{\circ} \mathrm{N}, 133^{\circ} \mathrm{E}\right)$. This ridge extension and the associated anticyclonic flow were considered to be a typical development of the Philippine Sea cold surge.

The downstream northeasterly flow reached the Philippines and seemed to have brought precipitation to the east coast of the Philippines on December 26. In the equatorial region between 0 and $15^{\circ} \mathrm{N}$, a westwardpropagating, cyclonic flow was observed near $150^{\circ} \mathrm{E}$ on December 21, near $140^{\circ} \mathrm{E}$ on December 23, and near $125^{\circ} \mathrm{E}$ on December 26 . The easterly flow at the northern edge of the cyclonic disturbance and the northeasterly flow associated with the cold surge formed a convergence zone offshore of the Philippines. The formation of a similar convergence zone due to a cold surge and a westward-propagating disturbance is considered to be a key driver of the heavy rainfall that occurs in autumn along the east coast of the Indochina Peninsula (Yokoi and Matsumoto 2008; Wu et al. 2011; Chen et al. 2012). 


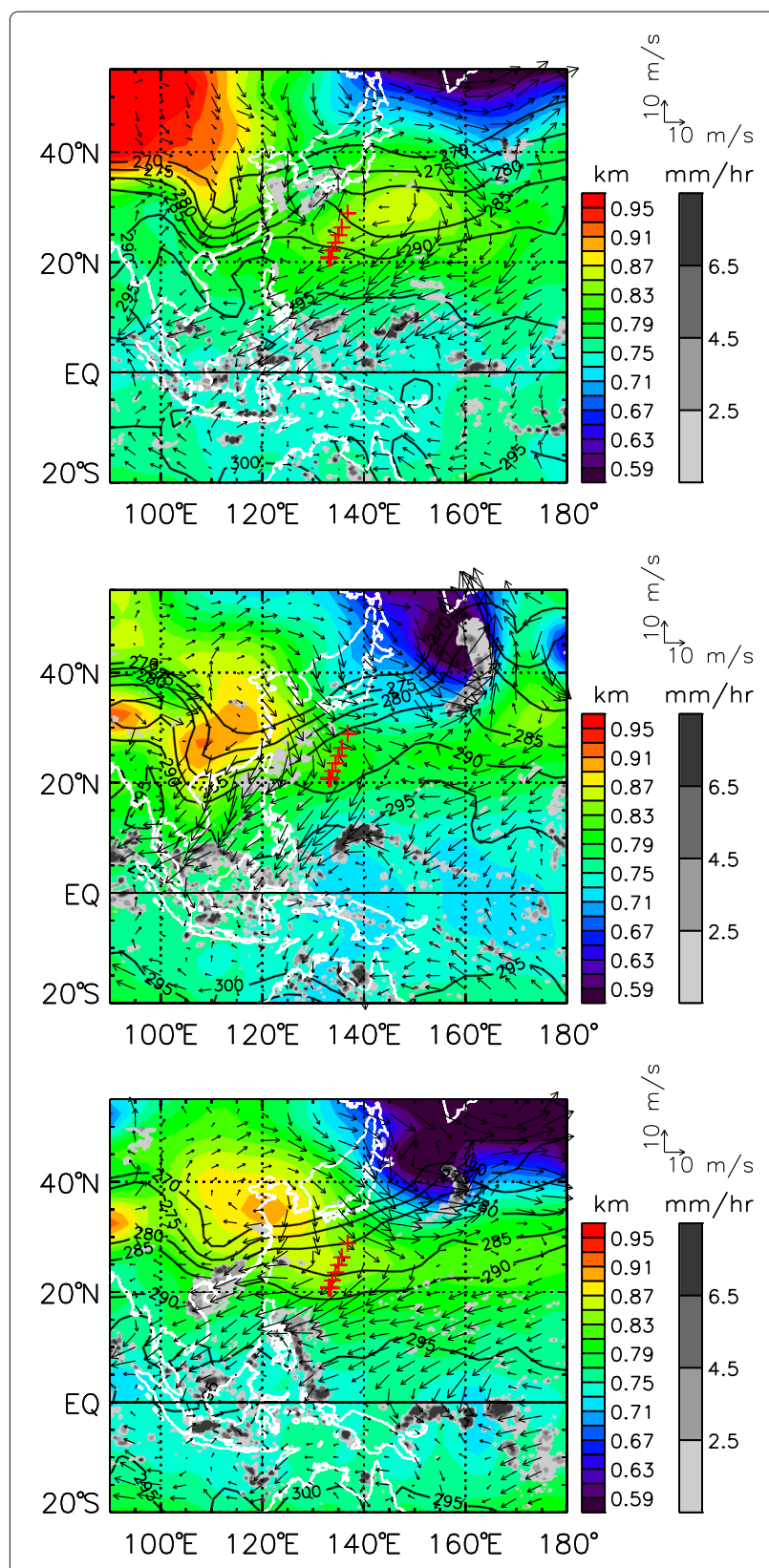

Fig. 2 Horizontal map of relevant meteorological variables during the Hakuho-maru observation period. The NCEP Reanalysis II geopotential height (color shading), temperature (Kelvin, black contours), horizontal wind (arrows), and TRMM 3B42 rainfall (gray shading) at the $925 \mathrm{hPa}$ level at (upper) 1200 UT on December 21, (middle) 0600 UT on December 23, and (lower) 0000 UT on December 26, 2012. The launch sites of the radiosondes from the R/V Hakuho-maru are indicated by red pluses

\section{Temperature and moisture variations obtained by the radiosondes}

During the observation period between December 23-24 (upper panel of Fig. 3), a stable layer with a large vertical potential temperature gradient formed at a height of about
$2 \mathrm{~km}$. Below this layer, the temperature and humidity were higher in the southern area.

From the fixed-point observations (lower panel of Fig. 3), the stable layer at a height of around $2 \mathrm{~km}$ gradually intensified. Below the stable layer, both the potential temperature and the water vapor mixing ratio showed uniform vertical distributions, which were consistent with the well-mixed layer during a cold surge event.

\section{Energy budget analysis}

Using the radiosonde data from the fixed-point observations combined with the operational radiosonde data at Minamidaitojima and Chichijima, we performed a thermodynamic energy budget analysis to evaluate the thermodynamic energy transfer between the atmosphere and ocean.

The fixed-point observations were conducted during the period when the near-surface temperature reached its minimum as shown in Fig. 4. The near-surface temperatures at Minamidaitojima and Chichijima decreased before December 25 and increased after December 26 along with the cold surge passage. The near-surface temperature observed by the radiosondes from the $R / V$ Hakuho-maru showed a temperature decrease between 1200 UT on December 24 and 1200 UT on December 25. We evaluated the thermodynamic and moisture budgets using the data obtained during this period. The area-average, near-surface temperature obtained from the radiosondes from the $\mathrm{R} / \mathrm{V}$ Hakuho-maru, and at Minamidaitojima and Chichijima showed a slight decrease. Note that the result of the AMTEX ' 74 budget analysis showed the maximum heat and moisture transport from the ocean to the atmosphere near the end of the temperature decrease associated with the cold surge.

Figure 5 shows the results of the evaluation using Eqs. (3) and (4). In the layer below $850 \mathrm{hPa}$, the horizontal advection terms of temperature and moisture $(-\overline{\boldsymbol{v} \cdot \nabla T}$, and $-\overline{\boldsymbol{v} \cdot \nabla q}$, respectively) and the individual changes in the temperature and moisture $(\delta T / \delta t$ and $\delta q / \delta t$, respectively) were large and had opposite signs, while the local temperature and moisture changes $(\partial \bar{T} / \partial t$ and $\partial \bar{q} / \partial t$, respectively) and the vertical advection terms of temperature and moisture $\left(\bar{\omega}\left(\partial \bar{T} / \partial p-R / C_{p} \bar{T} / p\right)\right.$ and $\bar{\omega} \partial \bar{q} / \partial p$, respectively) were small. This means the horizontal advection of cold and dry air was almost canceled by the vertical convergence of the eddy transport of temperature and moisture, resulting in the relatively small values of local changes in the temperature and moisture with time. This feature is consistent with the uniform vertical distribution of the potential temperature and water vapor mixing ratio observed with the R/V Hakuho-maru radiosondes shown in the previous section. 

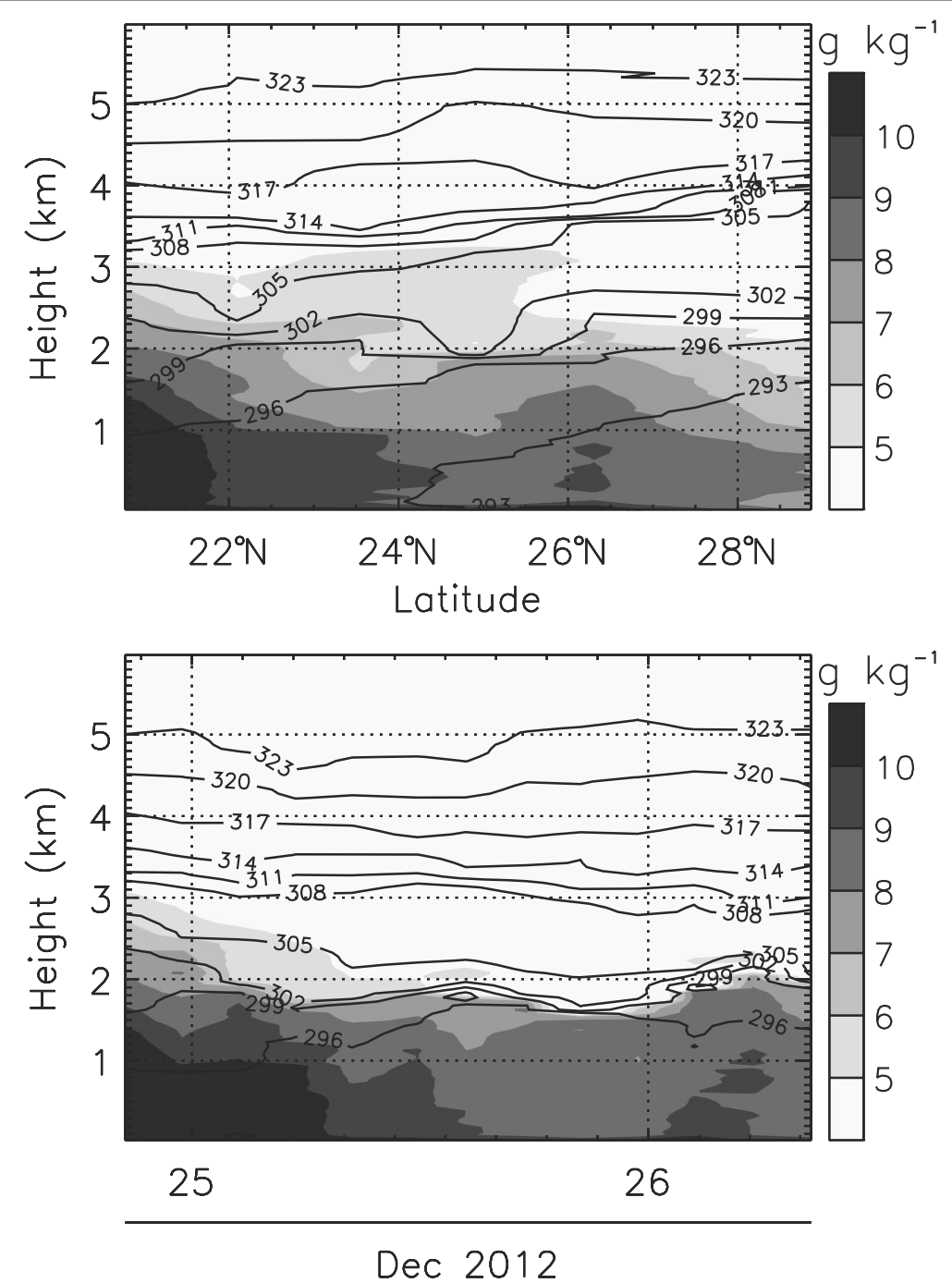

Fig. 3 The result of the radiosonde observation of the Hakuho-maru cruise. (Upper) Latitude-height section of water-vapor mixing ratio (gray shading) and potential temperature (black contours) from the moving observations from $29^{\circ} \mathrm{N}$ to $22^{\circ} \mathrm{N}$. (Lower) The same as the upper panel, except for the time-height cross-section during the fixed-point observation during December 24-26, 2012

In the layer between 850 and $700 \mathrm{hPa}$, the cold horizontal advection had a similar magnitude to the layer below $850 \mathrm{hPa}$, and it seemed to balance the warm vertical advection. For the moisture budget in the same layer between 850 and $700 \mathrm{hPa}$, both horizontal and vertical advection of dry air were observed. Although the local moisture change was negative, it did not fully compensate for the horizontal and vertical advection of dry air, resulting in the large positive value of the individual change in moisture. Although it is possible that this large individual change of moisture was not only due to eddy moisture transport but also due to evaporation, this possibility will not be discussed further in this study, because the effects of evaporation (and condensation) canceled out in the evaluation of the equivalent temperature, which we will show later.

In the layer above $700 \mathrm{hPa}$, the cold horizontal advection balanced the warm vertical advection. All the moisture terms in this layer were small.

The individual change of the equivalent temperature (left panel of Fig. 6) shows a large value in the layer below $850 \mathrm{hPa}$, and the value in the layer between 700 and $850 \mathrm{hPa}$ is comparable. The surface value of $F_{c}$, i.e., the total heat supply from the ocean to the atmosphere is estimated as $410 \mathrm{~W} / \mathrm{m}^{2} . F_{c}$ at $850 \mathrm{hPa}$ is estimated as $140 \mathrm{~W} / \mathrm{m}^{2}$. The results indicate that the thermal influence from the sea surface reached the $700-850 \mathrm{hPa}$ layer through the $850 \mathrm{hPa}$ level. 


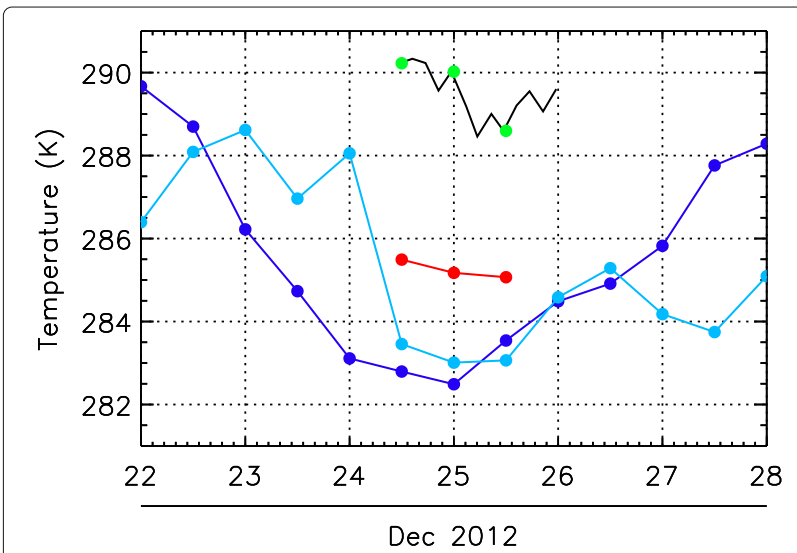

Fig. 4 Time series of the near-surface temperature during December 22-29, 2012. Values are the average between the surface and 850 hPa. (blue) Minamidaitojima, (light blue) Chichijima, (black) Hakuho-maru fixed-point observation data (3-hourly), (green filled circle) R/V Hakuho-maru data used in the budget analysis (12-hourly; 1200 UT on December 24, 0000 UT on December 25, and 1200 UT on December 25), (red) mean temperature obtained from the observations at the three site/stations (R/V Hakuho-maru, Minamidaitojima, and Chichijima)

\section{Discussion: comparison with AMTEX ' 74 results}

The energy budget in the layer below $850 \mathrm{hPa}$ was qualitatively similar to that observed during the cold period in AMTEX '74 when the temperature decreased due to a cold surge; that is, the strong horizontal advection of cold and dry air was almost balanced by the heating and moistening due to eddy transport, and the local temperature and moisture changes were very small. Quantitatively, each term in the thermal budget (Eq. (3)) of this study had about half of the magnitude of that during the AMTEX ' 74 cold period. For the moisture terms, the magnitudes of the
R/V Hakuho-maru observations were similar to or larger than those of AMTEX ' 74.

In Fig. 6, the individual change of the equivalent temperature and the eddy transport of the total heat energy obtained by the AMTEX ' 74 observations are indicated with dashed lines. The values were taken from Figs. 12 and 19 in Ninomiya (1975). The individual change of the equivalent temperature in the layer below $850 \mathrm{hPa}$ of this study (about $0.5 \mathrm{~K} / \mathrm{hr}$ ) is about $60 \%$ of the magnitude of the averaged value of the north and south areas during the AMTEX '74 cold period (about $0.8 \mathrm{~K} / \mathrm{hr}$ ). On the other hand, in the layer between 850 and $700 \mathrm{hPa}$, the value obtained in this study is larger than that for the northern area during the AMTEX ' 74 cold period, and close to that of the southern area. The difference in the individual change in the equivalent temperature between the surface $850 \mathrm{hPa}$ layer and the $850-700 \mathrm{hPa}$ layer is smaller than that in the AMTEX ' 74 cold period.

The eddy transport of the total heat energy at the surface of this study was about $410 \mathrm{~W} / \mathrm{m}^{2}$, which is smaller than, but comparable to, those of the northern area (about $450 \mathrm{~W} / \mathrm{m}^{2}$ ) and southern area (about $570 \mathrm{~W} / \mathrm{m}^{2}$ ) during the AMTEX ' 74 cold period, and about half of the maximum value (about $780 \mathrm{~W} / \mathrm{m}^{2}$ ) observed near the end of the AMTEX '74 cold period. The eddy transport estimated from the R/V Hakuho-maru observations is much larger than that of the AMTEX '74 warm period during February 23-27 when no cold surge was observed. The result suggests that a significant amount of heat exchange occurred even over the open ocean far from land.

\section{Conclusions}

We succeeded in observing the air-sea interactions associated with a cold surge event using radiosondes on
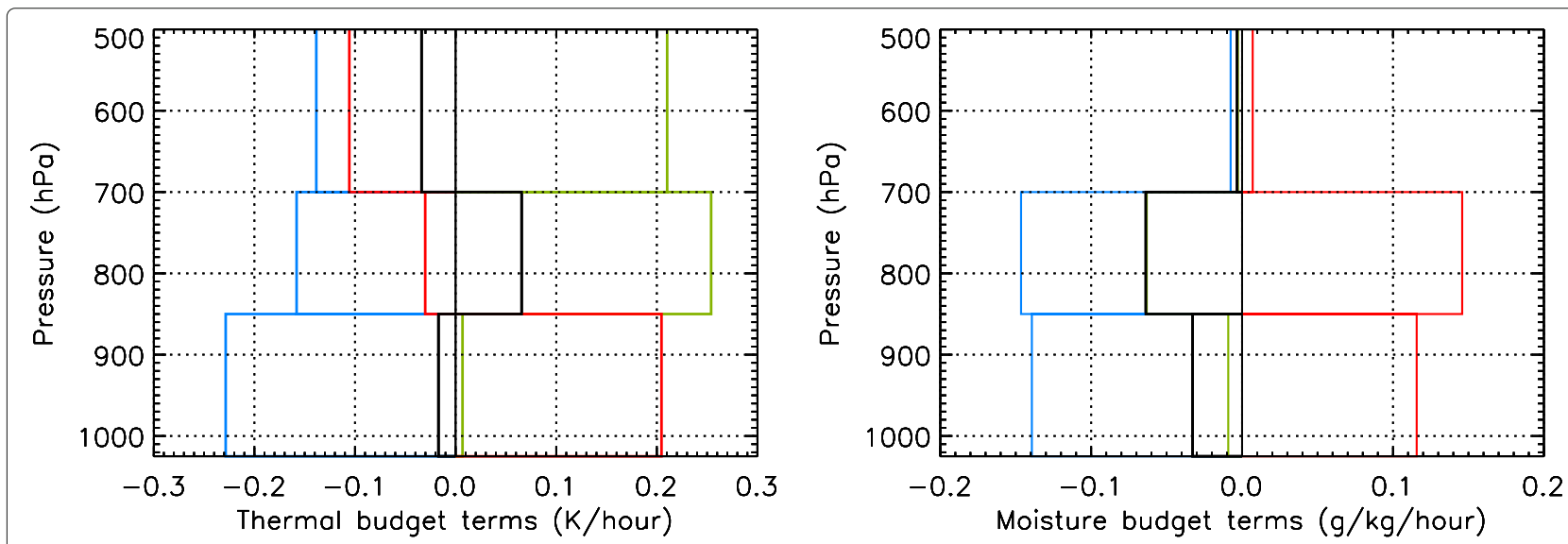

Fig. 5 Vertical profiles of the temperature and moisture budget. (Left) Local temperature change $\partial \bar{T} / \partial t$ (black), horizontal temperature advection $-\overline{\boldsymbol{v} \cdot \nabla T}$ (light blue), vertical temperature advection $-\bar{\omega}\left(\partial \bar{T} / \partial p-R / C_{p} \bar{T} / p\right)$ (green), and individual change in temperature $\delta T / \delta t$ (red). (Right) The same as the left panel, except for the moisture budget: local moisture change $\partial \bar{q} / \partial t$ (black), horizontal moisture advection $-\overline{\boldsymbol{v} \cdot \nabla q}$ (light blue), vertical moisture advection $-\bar{\omega}(\partial \bar{q} / \partial p)$ (green), and individual change in moisture $\delta q / \delta t$ (red) 

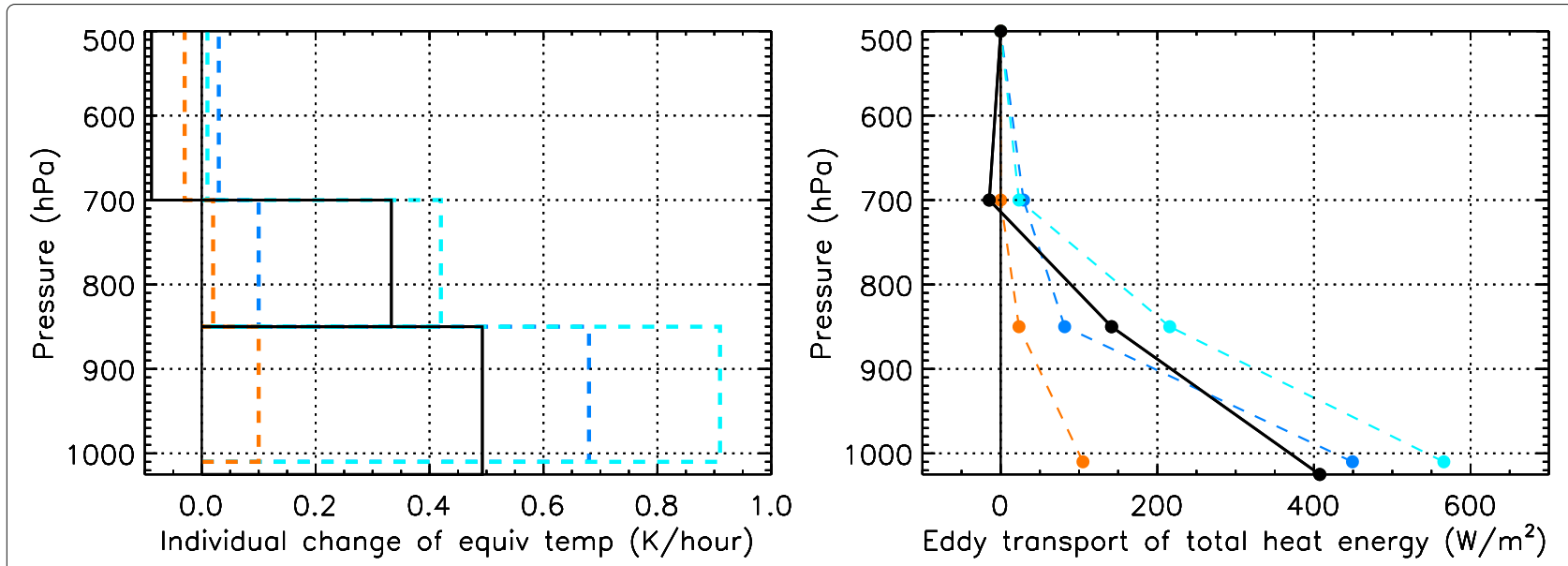

Fig. 6 Vertical profiles of results from R/V Hakuho-maru and AMTEX '74 observations. (Left) Individual change in the equivalent temperature. (Right) Eddy transport of the total heat energy. The results of the RN Hakuho-maru observations are plotted with solid black lines. The results from AMTEX '74 are plotted with dashed lines: (blue) the results over the north area during the cold period, (light blue) the results over the south area during the cold period, and (orange) the results during the warm period

the R/V Hakuho-maru far from land in the Philippine Sea in late December 2012. We evaluated the thermal energy transport from the sea surface to the atmosphere, and compared it with the results obtained from the AMTEX '74 experiment conducted over the East China Sea.

The strong horizontal advection of cold and dry air due to the cold surge dominated in the layer below $850 \mathrm{hPa}$. In spite of this strong horizontal advection, the local temperature and moisture changes were small, since the horizontal advection was balanced by a supply of heat and moisture from the sea surface, which is qualitatively the same finding as observed in the AMTEX '74 cold period. The eddy transport of the total heat energy from the sea surface to the atmosphere was estimated as about $410 \mathrm{~W} / \mathrm{m}^{2}$, which is roughly similar to the mean value (about $510 \mathrm{~W} / \mathrm{m}^{2}$ ) and about half of the maximum value (about $780 \mathrm{~W} / \mathrm{m}^{2}$ ) observed during the AMTEX ' 74 cold period.

This result shows the existence of considerable heat transfer from the sea surface over the Philippine Sea, in the region downstream of the cold surge after it passed through the East China Sea. The horizontal advection of cold and dry air had an effect on decreasing the local temperature and humidity, i.e., to suppress the convective instability. However, this effect was compensated by the eddy heat and moisture transport from the sea surface. As a result, the convective instability tended to be maintained, which, in the case of this study, possibly led to the enhanced convection and precipitation observed along the east coast of the Philippines.

In this study, it is also indicated that the coupling of the northeasterly flow due to the cold surge and the westward-propagating cyclonic disturbance strengthened the convergent flow toward the convective area over the Philippines. This type of coupling has been highlighted as one of the key drivers of heavy rainfall over the east coast of the Indochina Peninsula in autumn. The indication of a similar development mechanism over the Philippines is a key result of this study.

We hope to estimate the thermal budget during different phases of a cold surge and further south of the region considered in this study in order to understand the effect of cold surges on tropical convection as soon as we have collected the necessary data.

\section{Abbreviations}

AMTEX: Air mass transformation experiment; AMY: Asian monsoon years; NCEP: National Centers for Environmental Prediction; TRMM: Tropical rainfall measuring mission; VPREX: Vietnam Philippines rainfall experiment

\section{Acknowledgements}

We would like to thank Dr. Hodaka Kawahata (the University of Tokyo), Mr. Katsura Kameo (the University of Tokyo), Mr. Ei Hatakeyama (Marine Works Japan LTD), and all of the crew of the R/V Hakuho-maru for their great help during the radiosonde observations on board the research vessel. We wish to express our gratitude to Drs. Kaoru Sato (the University of Tokyo), Naohiko Hirasawa, and Yoshihiro Tomikawa (National Institute of Polar Research) for permitting us to use their balloon launcher.

\section{Funding}

Part of this study was supported by the Green Network of Excellence (GRENE) program of the Japanese Ministry of Education, Culture, Sports, Science and Technology and by Japan Agency for Marine-Earth Science and Technology.

\section{Authors' contributions}

SYO and JM proposed the topic, conceived and designed the study. SYO and PW carried out the radiosonde observations on board the research vessel "Hakuho-maru" with support by MH who provided the meteorological information during the "Hakuho-maru" cruise. $\mathrm{MH}, \mathrm{HK}, \mathrm{NE}$, and $\mathrm{TI}$ discussed the obtained results and provided comments on the manuscript. All authors read and approved the final manuscript.

\section{Competing interests}

The authors declare that they have no competing interest. 


\section{Publisher's Note}

Springer Nature remains neutral with regard to jurisdictional claims in published maps and institutional affiliations.

\section{Author details}

1 Japan Agency for Marine-Earth Science and Technology, 2-15 Natsushimacho, Yokosuka 237-0061, Japan. ${ }^{2}$ Present address: National Institute for Agro-Environmental Sciences, 3-1-3 Kannondai, Tsukuba 305-8604, Japan. ${ }^{3}$ Faculty of Science, Department of Earth and Planetary Sciences, Hokkaido University, Kita 10 Nishi 8, Kita-ku Sapporo 060-0810, Japan. ${ }^{4}$ Present address: Tokyo Metropolitan University, 1-1, Minami-Osawa, Hachioji 192-0397, Japan.

${ }^{5}$ Tokyo Metropolitan University, 1-1, Minami-Osawa, Hachioji 192-0397, Japan.

Received: 20 June 2017 Accepted: 28 December 2017

Published online: 06 February 2018

\section{References}

Chen T-C, Yen M-C, Tsay J-D, Tan Thanh NT, Alpert J (2012) Synoptic development of the Hanoi heavy rainfall event of 30-31 October 2008: Multiple-scale processes. Mon Wea Rev 140:1219-1240. https://doi.org/10. 1175/MWR-D-11-00111.1

Compo GP, Kiladis GN, Webster PJ (1999) The horizontal vertical structure of east Asian winter monsoon pressure surges. Q J R Meteorol Soc 125:29-54

Davies-Jones R (1993) Useful formulas for computing divergence, vorticity, and their errors from three or more stations. Mon Wea Rev 121:713-725. https://doi.org/10.1175/1520-0493(1993)121<0713:UFFCDV> 2.0.CO;2

Kanamitsu M, Ebisuzaki W, Woollen J, Yang S-K, Hnilo JJ, Fiorino M, Potter GL (2002) NCEP-DOE AMIP-II Reanalysis (R-2). Bull Amer Meteor Soc 83:1631-1643. https://doi.org/10.1175/BAMS-83-11-1631

Katayama A (1967) On the radiation budget of the troposphere over the northern hemisphere (iii) - Zonal cross-section and energy consideration-. J Met Soc Japan 45:26-39

Kummerow C, Simpson J, Thiele O, Barnes W, Chang ATC, Stocker E, Adler RF, Hou A, Kakar R, Wentz F, Ashcroft P, Kozu T, Hong Y, Okamoto K, Iguchi T, Kuroiwa H, Im E, Haddad Z, Huffman G, Ferrier B, Olson WS, Zipser E, Smith EA, Wilheit TT, North G, Krishnamurti T, Nakamura K (2000) The status of the tropical rainfall measuring mission (TRMM) after two years in orbit. J Appl Meteor 39:1965-1982. https://doi.org/10.1175/1520-0450(2001)040<1965: TSOTTR $>2.0 . C O ; 2$

Ninomiya K (1975) Large-scale aspects of air-mass transformation over the East China Sea during AMTEX '74. J Met Soc Japan 53:285-303

Wang B, Matsumoto J, Wu G, Li J (2010) The Science Plan for Asian Monsoon Years (AMY 2007-2012), A Cross-cutting WCRP Initiative. China Meteorological Press, Beijing

Wu P, Fukutomi Y, Matsumoto J (2011) An observational study of the extremely heavy rain event in northern Vietnam during 30 October-1 November 2008. J Met Soc Japan 89A:331-344. https://doi.org/10.2151/jmsj.2011-A23

Yokoi S, Matsumoto J (2008) Collaborative effects of cold surge and tropical depression-type disturbance on heavy rainfall in central Vietnam. Mon Wea Rev 136:3275-3287

\section{Submit your manuscript to a SpringerOpen ${ }^{\circ}$ journal and benefit from:}

- Convenient online submission

- Rigorous peer review

- Open access: articles freely available online

- High visibility within the field

- Retaining the copyright to your article

Submit your next manuscript at $\gg$ springeropen.com 